\title{
Differential Host Cell Gene Expression and Regulation of Cell Cycle Progression by Nonstructural Protein 11 of Porcine Reproductive and Respiratory Syndrome Virus
}

\author{
Yan Sun, ${ }^{1,2}$ Dong Li, ${ }^{1}$ Sumanprava Giri, ${ }^{3}$ Supriya G. Prasanth, ${ }^{3}$ and Dongwan Yoo $^{1}$ \\ ${ }^{1}$ Department of Pathobiology, University of Illinois at Urbana-Champaign, 2001 South Lincoln Avenue, Urbana, IL 61802, USA \\ ${ }^{2}$ Department of Pathobiology, University of Pennsylvania, 380 South University Avenue, Philadelphia, PA 19104, USA \\ ${ }^{3}$ Department of Cell and Developmental Biology, University of Illinois at Urbana-Champaign, Urbana, IL 61801, USA \\ Correspondence should be addressed to Dongwan Yoo; dyoo@illinois.edu
}

Received 17 October 2013; Accepted 7 January 2014; Published 26 February 2014

Academic Editor: Raymond Rowland

Copyright (C) 2014 Yan Sun et al. This is an open access article distributed under the Creative Commons Attribution License, which permits unrestricted use, distribution, and reproduction in any medium, provided the original work is properly cited.

\begin{abstract}
Nonstructural protein 11 (nsp11) of porcine reproductive and respiratory syndrome virus (PRRSV) is a viral endoribonuclease with an unknown function. The regulation of cellular gene expression by nspll was examined by RNA microarrays using MARCnspl1 cells constitutively expressing nspl1. In these cells, the interferon- $\beta$, interferon regulatory factor 3 , and nuclear factor- $\kappa \mathrm{B}$ activities were suppressed compared to those of parental cells, suggesting that nspll might serve as a viral interferon antagonist. Differential cellular transcriptome was examined using Affymetrix exon chips representing 28,536 transcripts, and after statistical analyses 66 cellular genes were shown to be upregulated and 104 genes were downregulated by nspl1. These genes were grouped into 5 major signaling pathways according to their functional relations: histone-related, cell cycle and DNA replication, mitogen activated protein kinase signaling, complement, and ubiquitin-proteasome pathways. Of these, the modulation of cell cycle by nspll was further investigated since many of the regulated genes fell in this particular pathway. Flow cytometry showed that nspl1 caused the delay of cell cycle progression at the $\mathrm{S}$ phase and the BrdU staining confirmed the cell cycle arrest in nspll-expressing cells. The study provides insights into the understanding of specific cellular responses to nspll during PRRSV infection.
\end{abstract}

\section{Introduction}

Porcine reproductive and respiratory syndrome (PRRS) is one of the most significant infectious diseases for the pig industry worldwide and causes severe economic losses [1]. The etiological agent is PRRS virus (PRRSV), which belongs to the family Arteriviridae in the order Nidovirales [2] and possesses a single-stranded positive-sense RNA genome of $15.4 \mathrm{~kb}$ in size [3-6]. Two distinct genotypes have been reported for PRRSV: European (type I) and North American (type II) genotypes [7, 8]. The PRRSV genome contains 10 open reading frames (ORFs) including the newly identified ORF5a $[9,10]$. ORFla is translated to produce the PPla polyproteins, but ORF1b is expressed as a fusion with ORFla by ribosomal frameshifting and produces the PPla/b fusion polyproteins. PPla and PPla/b are cotranslationally processed into 14 cleavage products. These products are nonstructural proteins (nsps) that are believed to participate in viral genome replication and subgenomic mRNA transcription [11-13]. Of these, nspll is a 223 amino acid protein and contains a nidovirus-specific domain, termed NendoU, in the Cterminal region. NendoU is known to contain an endoribonuclease activity and consists of two subdomains, A and B $[4,14-16]$. Mutational studies using equine arteritis virus (EAV) nspll, which is a homolog of PRRSV nspll, show that three enzymatically catalytic sites reside in subdomain A, while two aspartic acids in subdomain $B$ are responsible for the overall protein structure [16]. In EAV, nsp1l plays a key role in viral RNA synthesis and thus it may also be essential for PRRSV replication. Recently, PRRSV has been shown to modulate type I IFN response [17] and nspll has been suggested to participate in the modulation of IFN response [18]. 
Cellular transcriptional profiles during PRRSV infection have been studied to some extent $[19,20]$. However, such studies do not identify specific viral proteins responsible for gene expressions changes, and thus the present study was conducted to understand the specific cellular response to nspl1 in cells stably expressing the protein using RNA microarrays. Based on the microarray data, five major cellular pathways were identified to be regulated by nspll, and of the five pathways the cell cycle pathway was examined. We provide the evidence that PRRSV nspll protein participates in modulating the cell cycle progression at the $S$ phase.

\section{Materials and Methods}

2.1. Cells. MARC-145 is a subcloned cell line of MA-104 which was derived from African green monkey kidney [21]. MARC-145 is the only established cell line permissive for PRRSV replication and thus widely used for the study of PRRSV in vitro. MARC-145 and MARC-nspll cells were maintained in Dulbecco's modified Eagle's medium (DMEM; Mediatech Inc., Manassas, VA, USA) containing 10\% heatinactivated fetal bovine serum (FBS; HyClone, Logan, UT, USA) in a humidified incubator with $5 \% \mathrm{CO}_{2}$ at $37^{\circ} \mathrm{C}$.

2.2. Plasmids, Antibodies, and Chemicals. The nspll coding sequence was PCR-amplified from the FL12 strain of PRRSV and was inserted into the retroviral expressing vector pLNCX2 (Clontech) and mammalian expression vector pXJ41 with a FLAG tag at its N-terminus using the following primers: forward $5^{\prime}$-AAACTCGAGGCCACCATGGGGTCGAGCTCCCCGCTCCC-3' and reverse $5^{\prime}$-GCGGCCGCTTACTTATCGTCGTCATCCTTGTAATCTTCAAGTTGAAAATAGGC-3'. The translation initiation and termination codons were added to the nspll coding sequence. The anti-FLAG monoclonal antibody (MAb M2, Sigma) and the anti-BrdU antibody were purchased from Sigma (St. Louis, MO, USA). Bromodeoxyuridine (5-bromo-2'-deoxyuridine, $\mathrm{BrdU}$ ) is a synthetic nucleoside that is an analog of thymidine and is commonly used in the detection of proliferating cells. Polyinosinic:polycytidylic (poly [I:C]) as a double-stranded RNA analog was purchased from Sigma. A donkey antirabbit antibody conjugated with Texas Red and a goat antimouse antibody conjugated with FITC were purchased from Invitrogen (Carlsbad, CA, USA). The nspll-specific rabbit antibody was generated in our laboratory using recombinant proteins described as follows.

2.3. Recombinant Protein Preparation. Since wild-type nspl1 seemed to be toxic in E. coli [15], the NendoU nspll mutant (nsp11-K3779A), was subcloned into the E. coli expression vector pET-28a+ with the His-tag at both termini, and this plasmid was transformed into $E$. coli BL21. A $5 \mathrm{~mL}$ overnight culture was started using LB broth containing ampicillin $(1 \mu \mathrm{L} / \mathrm{mL})$ by inoculating with transformed bacteria at $37^{\circ} \mathrm{C}$ with vigorous agitation. In the following morning, $500 \mathrm{~mL}$ of $2 \mathrm{xYT}$ ( $16 \mathrm{~g}$ of tryptone, $10 \mathrm{~g}$ of yeast extract, and $5 \mathrm{~g}$ of $\mathrm{NaCl}$ per L) containing ampicillin was inoculated with the $5 \mathrm{~mL}$ overnight culture. The culture was incubated at $37^{\circ} \mathrm{C}$ for approximately $4 \mathrm{~h}$ and when the optical density at 600 reached $0.6-0.8$, protein expression was induced by adding IPTG up to $1 \mathrm{mM}$ concentration. The culture was incubated for additional $2 \mathrm{~h}$. Cells were pelleted by centrifugation at $7700 \times \mathrm{g}$ for $10 \mathrm{~min}$ at $4^{\circ} \mathrm{C}$. The cells were resuspended in $12.5 \mathrm{~mL}$ of STE ( $5 \mathrm{~mL}$ of $1 \mathrm{M}$ Tris- $\mathrm{HCl}, \mathrm{pH} 8.0,150 \mathrm{~mL}$ of $0.5 \mathrm{M}$ $\mathrm{NaCl}$ and $1 \mathrm{~mL}$ of $0.5 \mathrm{M}$ EDTA, pH 8.0 in $500 \mathrm{~mL})$ containing aprotinin $(1-10 \mu \mathrm{g} / \mathrm{mL})$ and PMSF $(1 \mathrm{mM})$ and pelleted again at $7700 \times \mathrm{g}$ for $10 \mathrm{~min}$. The cells were resuspended again in $12.5 \mathrm{~mL}$ of $1 \mathrm{X}$ PBS, and DNase I $(20 \mu \mathrm{g} / \mathrm{mL})$ and lysosome $(200 \mu \mathrm{g} / \mathrm{mL})$ were added and treated for $1 \mathrm{~h}$. Then, DTT was added to make a final concentration of $5 \mathrm{mM}$ and incubate 5 min on ice. $20 \%$ of Sarkosyl solution was additionally added to a final concentration of $0.5 \%$, followed by sonication to sheer the genomic DNA at the setting scale of 4 for $10 \mathrm{~s}$ at least three times (Soniprep 150; Sanyo Gallenkamp PLC, Leicester, UK). After sonication, the samples were centrifuged at 12,000 rpm for $30 \mathrm{~min}$ (J2-21; Beckman Coulter, Brea, CA, USA), and supernatants and pellets were collected separately and subjected to SDS-PAGE individually to determine the presence of nsp11-K3779A protein for each fraction. Nsp11 was purified from the supernatants and concentrated to $1 \mathrm{mg} / \mathrm{mL}$ using the HisTrap column according to the manufacturer's instruction (GE Healthcare Life Sciences, Piscataway, NJ, USA). A total of $2 \mathrm{mg}$ of nspll was used to immunize a rabbit 5 times at 2-week intervals, intramuscularly using Freund's incomplete and complete adjuvants, and an antiPRRSV-nsp11 rabbit serum was generated (Immunological Research Center, University of Illinois, Urbana, IL, USA). The specificity of the antiserum was determined by immune-blot and immunofluorescence using PRRSV-infected MARC-145 cells.

2.4. Establishment of nsp11-Expressing Cells (MARC-nsp11). MARC-145 cells were transduced with the nspll gene using the retroviral gene transfer system (Clontech). Briefly, $0.5 \mu \mathrm{g}$ of the pLNCX2-FLAG-nsp1l plasmid was cotransfected with pVSV-G into the pantropic packaging cell line GP2-293 to produce infectious lentivirus containing the PRRSV nsp11 gene. After $48 \mathrm{~h}$ of incubation, culture supernatants were collected and used to infect MARC-145 cells. Nsp11 geneintegrated cells were selected using $1 \mathrm{mg} / \mathrm{mL}$ of G418 (Invitrogen) for approximately 2 weeks with fresh G418 every 4 days. When the majority of cells has died, G418-resistant cell colonies were picked using cloning cylinders and were amplified as putative nspll-expressing cells. Seven clones were initially selected and individually amplified. One clone was chosen and designated as MARC-nsp11 for subsequent studies.

2.5. PCR, RT-PCR, and Quantitative PCR. For PCR, cellular DNA was extracted from MARC-nspll cells using QIAamp DNA kit (Qiagen) and PCR was performed to determine the nspll gene integration. For reverse transcription (RT), total cellular RNA was extracted using Trizol (Invitrogen) and was treated with RQ1 RNase-free DNase I (Promega) followed by RT using the nspll-specific reverse primer and PCR using the primer set as described above. Quantitative (q) PCR 
was performed using ABI Prism 7000 Sequence Detection System and Software (Applied Biosystems) in a final volume of $25 \mu \mathrm{L}$ containing $2.5 \mu \mathrm{L}$ of cDNA synthesized from the RT reaction, $2.5 \mathrm{pmol}$ of each primer, $12.5 \mu \mathrm{L}$ of SYBR Green Master Mix (Applied Biosystems), and $5 \mu \mathrm{L}$ of water. The primer sequences were designed using Primer 5.0 Software (Invitrogen) or obtained from previous reports (Table 2). The amplification parameters were 40 cycles of two steps, each step comprised of heating at $95^{\circ} \mathrm{C}$ and extension at $60^{\circ} \mathrm{C}$. The final mRNA levels of target genes were normalized using GAPDH as a house keeping gene.

2.6. Immunoprecipitation. Typically, $100 \mu \mathrm{L}$ of total cell lysates was incubated with $1 \mu \mathrm{L}$ of the anti-nspll rabbit serum at $4^{\circ} \mathrm{C}$ overnight. Reactions were incubated with Protein $\mathrm{A}$ Sepharose beads (GE Healthcare) at $4^{\circ} \mathrm{C}$ for $4 \mathrm{~h}$. Following centrifugation for $5 \mathrm{~min}$, supernatants were aspirated and washed with the lysis buffer twice. The beads were mixed with the loading buffer, boiled, and subjected to $12 \%$ SDS-PAGE followed by transfer to Immobilon-P membrane (Millipore). After blocking membranes with $5 \%$ skim milk powder dissolved in TBS-T (10 mM Tris- $\mathrm{HCl}$ [pH 8.0], $150 \mathrm{mM} \mathrm{NaCl}$, $1 \%$ Tween 20) for $1 \mathrm{~h}$ at room temperature, membranes were incubated with the anti-FLAG antibody in TBS-T containing $5 \%$ skim milk powder at $4^{\circ} \mathrm{C}$ overnight. After 5 washes with TBS-T, membranes were incubated with a horseradish peroxidase-conjugated anti-mouse antibody for $1 \mathrm{~h}$ at room temperature. Membranes were washed 5 times again and proteins were visualized using the ECL detection system (Thermo, Minneapolis, MN, USA).

2.7. Dual Luciferase Reporter Assays. Double-strand RNA stimulation was conducted using poly (I:C). For nspl1gene transfection, MARC-145 cells were seeded in 12-well plates and per well, $0.05 \mu \mathrm{g}$ of pRL-TK, $0.5 \mu \mathrm{g}$ of pIFN- $\beta$ luc, pIRF3-luc or pPRDII-luc, and $0.5 \mu \mathrm{g}$ of pXJ41-FLAGnspl1 were cotransfected using Lipofectamine 2000 according to the manufacturer's instruction (Invitrogen). For MARCnspl1 cells, pRL-TK and each of the three reporter plasmids were cotransfected with the same amount as that of the nspll gene transfection. Twenty-four hours after transfection, $0.5 \mu \mathrm{g}$ of poly (I:C) was transfected into cells for $16 \mathrm{~h}$. Cells were lysed using the passive lysis buffer (Promega), and supernatants were measured for luciferase activities using the Dual Luciferase Reporter Assay System (Promega) in the luminometer (Wallac 1420 Victor multilabel counter, Perkin Elmer, Waltham, MA, USA).

2.8. RNA Microarray Design and Data Analyses. MARC145 and MARC-nsp11 cells were seeded one day prior to experiments and total cellular RNAs were extracted using Trizol (Invitrogen) and purified by RNeasy mini kit (Qiagen). The quantity and quality of RNA were determined using an Align 2100 bioanalyzer (Agilent Technologies, Palo Alto, CA). The RNA samples were then subjected to microarray using Human Gene 1.0 ST arrays (Affymetrix UK Ltd., High Wycombe, UK) at Keck Biotechnology Center (University of Illinois, Urbana, IL). The microarray was repeated twice in triplicate each. For data analyses, quality control assessments, data processing, and statistical analyses were conducted using the package from the Bioconductor project [22] as indicated below. The Affymetrix's Human Gene 1.0 ST array contained probes to interrogate 253,002 exons representing 28,536 annotated genes. Comparisons were made either on the exonlevel to investigate alternative splicing or on the whole genelevel to summarize all transcripts of the gene. The individual probe values were background-corrected, normalized, and summarized into one value at both the exon- and genelevels using the robust multiarray average (RMA) algorithm available from the oligo packages [23]. Testing for differential gene expressions between MARC-145 cells and MARC-nsp11 cells was conducted separately at the exon- and gene-levels by fitting a linear model including a term to account for the separate processing batches using the Linear Models for Microarray Data (Limma) package [24, 25]. The criteria for significance varied for the exon- and gene-levels. At the exonlevel, the criteria were at least a 2 -fold change and a raw $P$ value $<0.02$, resulting in 8,693 significant exons. At the gene-level, the Limma model was fit and raw $P$ values were calculated using all genes on the array, but the correction for multiple hypothesis testing using the FDR (false discovery rate) method [26] was done for only the 9,241 genes that varied in expression across all the samples of at least a 1.5-fold change. The criteria used to select significant genes within the filtered database for upregulation and downregulation were FDR $P$ value $<0.1$ and fold change $>2$ or $<-2$, respectively.

2.9. Flow Cytometry and Cell Cycle Analysis. Identical numbers of MARC-145 cells and MARC-nsp11 cells were seeded and grown for $24 \mathrm{~h}$ in DMEM containing $10 \%$ FBS. For flow cytometry, cells were collected by trypsinization, washed with PBS, and resuspended in cold PBS to $1 \times 10^{6}$ cells per mL. The cell suspension was added dropwise to an equal volume of cold ethanol with continuous agitation. After overnight incubation at $4^{\circ} \mathrm{C}$, its cellular DNA was stained with $10 \mu \mathrm{g} / \mathrm{mL}$ propidium iodide (PI) prepared in PBS containing $0.1 \%$ Triton X-100 and $10 \mu \mathrm{g} / \mathrm{mL}$ RNase A (Roche) for $30 \mathrm{~min}$ at room temperature in the dark. Samples were then analyzed by flow cytometry (BD AccuriC6, BD Accuri Cytometers, Ann Arbor, MI, USA), and the data were analyzed using FACS Express software supplied from Keck Biotechnology Center (University of Illinois, Urbana, IL, USA).

2.10. BrdU Incorporation and Immunofluorescence Assay. DNA synthesis in proliferating cells was determined using (BrdU) bromodeoxyuridine incorporation since its incorporation to DNA occurs during the $S$ phase. Cells were seeded on cover slips at a density of $1 \times 10^{5}$ cells/cover slip $(10 \mathrm{~mm} \times 10 \mathrm{~mm})$ and allowed to rest for $24 \mathrm{~h}$. The medium was removed and cells were incubated for a $10 \mathrm{~min}, 20 \mathrm{~min}$, or $24 \mathrm{~h}$ pulse in the BrdU labeling medium. For the $10 \mathrm{~min}$ and $20 \mathrm{~min}$ pulses, $10 \mu \mathrm{M}$ of BrdU was applied, and for the $24 \mathrm{~h}$ pulse $100 \mathrm{nM}$ of BrdU was applied. After BrdU incubation, cells were fixed in 2\% paraformaldehyde in PBS for $15 \mathrm{~min}$ and washed with PBS three times. Cells were then permeabilized with $0.5 \%$ Triton $\mathrm{X}-100$ for 7 min on ice 
followed by blocking with $1 \%$ normal goat serum (NGS) in PBS three times, 10 min each. To observe the nuclei of cells, an anti-lamin $(1: 200)$ rabbit antibody was used as the primary antibody for $1 \mathrm{~h}$ in PBS containing 1\% NGS, and cells were incubated with a donkey anti-rabbit antibody conjugated with Texas-red (1:1000) for $30 \mathrm{~min}$. Followed by washing four times, $5 \mathrm{~min}$ each, $2 \%$ paraformaldehyde was used again to fix the bound antibodies. Cells were then incubated with $4 \mathrm{~N}$ $\mathrm{HCl}$ for $25 \mathrm{~min}$ at room temperature to denature DNA and to allow the BrdU antibody to recognize the incorporated BrdU in the nuclei. After three 10 min washes with PBS and two $10 \mathrm{~min}$ washes with $1 \%$ NGS in PBS, an anti-BrdU monoclonal antibody (1:500) was applied to cells for $90 \mathrm{~min}$. Cells were then incubated with a goat anti-mouse antibody conjugated with FITC $(1: 600)$ for $30 \mathrm{~min}$. Washing with PBS was applied four times after every incubation with antibodies. The cover slips were mounted on microscope slides in the mounting buffer and visualized using a Zeiss Axio Imager zl fluorescence microscope (Carl Zeiss Inc.) equipped with Chroma filters (Chroma Technology). Images were collected using AxioVision Software (Zeiss) and Hamamatsu ORCA cooled CCD camera. The BrdU-incorporated cells and a total number of lamin-positive cells were counted for both MARC-145 and MARC-nsp11 cells, and the \% of BrdU incorporation was calculated using the formula as follows: $\% \mathrm{BrdU}$ incorporation $=$ (number of double-positive cells for BrdU and lamin $) /(200$ lamin-positive cells $) \times 100$. The cell counting areas were selected randomly on slides and 200 lamin-positive cells were counted.

\section{Results}

3.1. Establishment of MARC-nsp11 Cells Stably Expressing nsp11 Protein. To study the regulatory role of PRRSV nsp11 in cellular processes, a cell line was established to constitutively express the nsp11 protein. MARC-145 was used as the parental cell line, since it is one of only few cell lines permissive for PRRSV infection. MARC-145 cells were infected with the lentivirus containing the nspll gene from PRRSV strain FL12 and G418 (neomycin)-resistant cells were selected. A total of seven drug-resistant clones were obtained and they were individually propagated for analyses. Cellular DNA was extracted from each clone, and PCR was conducted to determine gene integration. All clones were PCR-positive for nsp11 (Figure 1(a)), and cell clone "a" was chosen for further characterization and designated MARC-nspll. The chosen cell clone was examined for nspll mRNA by RT-PCR using primers indicated in Table 2, and a $660 \mathrm{bp}$ fragment was specifically amplified (Figure 1(b)). The nsp11 protein expression was also determined by immunoprecipitation using a rabbit anti-nsp11 antibody. A $26 \mathrm{kD}$ protein was specifically identified in MARC-nsp11 cells at a low level (Figure 1(c), lane 3), and the same size protein was identified in nspl1 gene-transfected cells (Figure 1(c), lane 2), demonstrating the expression of nspll in these cells.

3.2. Suppression of Type I IFN Induction by nsp11. PRRSV nspll contains the NendoU domain which is a common motif associated with an endoribonuclease activity for viruses in the order Nidoviridae [14, 15, 27]. Furthermore, PRRSV nsp11 has recently been suggested as a potential type I interferon (IFN) regulator $[17,18]$. Thus, the regulatory function of nsp11 for IFN induction was first examined in MARC-nspll cells and in MARC-145 cells transfected with the nspll gene. Cells were transfected with the pIFN- $\beta$-luc reporter plasmid and stimulated with poly (I:C) to examine the IFN induction (Figure 2(a)). While the cells transfected with the empty vector pXJ41 showed an efficient induction of luciferase activity of up to $\sim 16$-fold after stimulation, nspl1-expressing cells exhibited a strong suppression of the activity down to $\sim 4$-fold at the most $(P<0.01)$. The nspl1-mediated IFN suppression was dose-dependent (Figure 2(a)).

IFN expression is tightly regulated by IRFs (interferon regulatory factors), nuclear factor (NF)- $\kappa \mathrm{B}$, and activator protein (AP)-1 transcription factors. Among these, IRFs and $\mathrm{NF}-\kappa \mathrm{B}$ are major players regulating the formation of IFN enhanceosome and the IFN- $\beta$ production, and thus we first examined the IFN regulatory activities of nspll in MARC145 cells by gene transfection using pIRF3-luc and pPRDIIluc reporter plasmids. pIRF3-luc contains 4 copies of the IRF3-binding sequence, while pPRDII-luc contains 2 copies of the NF- $\kappa$ B binding sequence upstream of the luciferase gene. When cells were stimulated, the IRF3 reporter activity was increased by $\sim 14$-fold (Figure 2(b)). In the presence of nsp11, however, the IRF3 activity was decreased by 7 -fold $(P<0.005)$ compared to the activity in the absence of nsp11 (Figure $2(\mathrm{~b})$ ). Similarly, the NF- $\kappa \mathrm{B}$ reporter activity was increased by approximately 10 -fold after stimulation, but in the presence of nsp11, this activity was deceased by 2 -fold $(P<0.005)$ compared to the activity in the absence of nspl1 (Figure 2(c)). These results show the suppression of IRF3 and NF- $\kappa$ B induction by nspl1.

To examine whether MARC-nsp11 cells expressing nsp11 were biologically active, the IFN- $\beta$, IRF3, and NF- $\kappa$ B activities were determined after stimulation with poly (I:C) using the corresponding reporter constructs (Figure 2(d)). MARCnspll cells (black bars) showed the decrease of luciferase activities compared to those of empty vector-transfected (gray bars) or mock-transfected (white bars) MARC-145 cells. The suppressive activities in MARC-nsp11 were less markedly than those in gene-transfected cells and this was probably due to the lower level expression of nsp11 in MARCnsp11 cells. The reporter activities of IFN- $\beta$, IRF3, and NF$\kappa \mathrm{B}$ were reduced by $\sim 2,2$, and 2.5 -fold, respectively $(P<$ 0.05). This indicates that nsp11 in MARC-nspll cells was biologically active and retained the modulatory activity for IFN induction.

3.3. Transcriptome Analysis in MARC-nsp11 Cells. To examine the transcription regulation of host cells by nsp11, an RNA microarray was conducted in MARC-nspll cells using human gene exon chips. These chips contained 253,002 exons from 28,536 annotated genes. After microarray analyses, genes were filtered by fold changes greater than 1.5 , and 9,241 genes were initially identified to have been altered, among which 66 and 104 cellular genes were upregulated 


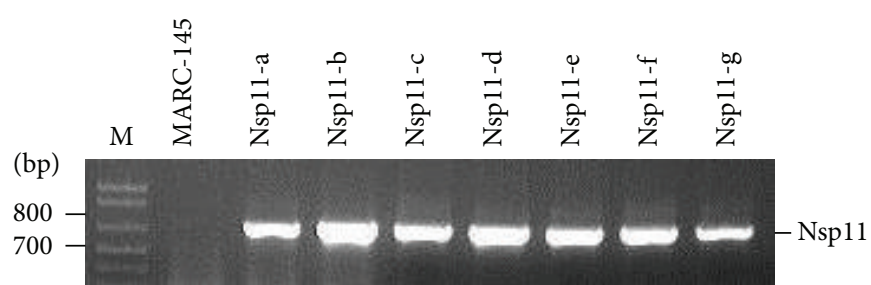

(a)

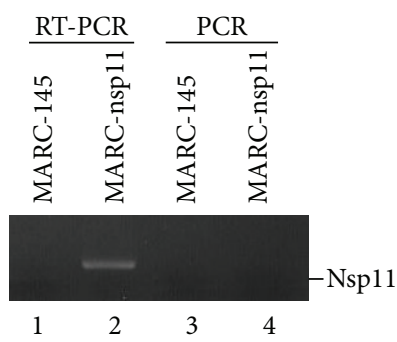

(b)

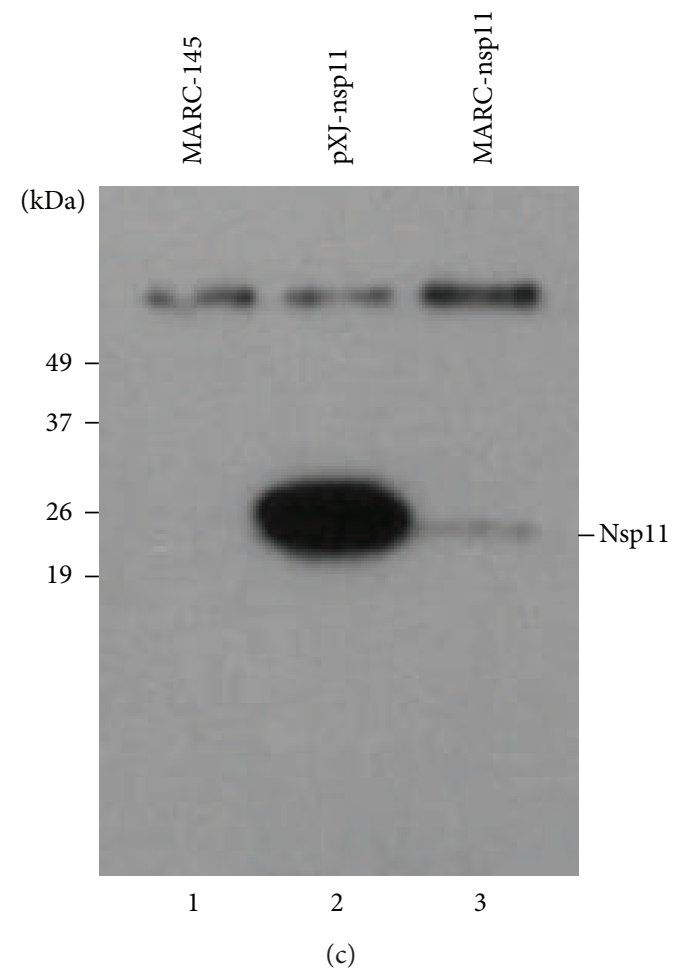

FIGURE 1: Establishment of MARC-nspll cells stably expressing PRRSV nspl1. (a) Incorporation of nspll gene in cellular DNA and identification of cell clones. A total of 7 clones, designated nspl1-a through nspl1-g, were obtained and screened for nspll sequence by PCR. Cellular DNA was extracted and PCR was performed using the primers described in Materials and Methods. The nspl1-a clone was chosen to conduct RT-PCR (b) and immune-blot (c) and designated as MARC-nsp1l cells. (b) Total cellular RNA was extracted from MARC-145 and MARC-nspll cells and subjected to DNase I treatment followed by RT-PCR or PCR. (c) Cell lysates were prepared from MARC-145 (lane 1), nsp11-gene transfected MARC-145 (lane 2), and MARC-nsp11 (lane 3) cells and were incubated with Protein A Sepharose beads and anti-rabbit nspll-specific polyclonal Ab, followed by immunoblot using anti-FLAG monoclonal Ab.

and downregulated, respectively, under the criteria of a fold change of 2 or greater and a false discovery rate (FDR) of $10 \%$. Based on the Database for Annotation, Visualization, and Integrated Discovery (DAVID), 79 of the significantly regulated genes were placed into 17 categories, some of which shared the common function. According to their functional correlations, the functional groups were summarized into five major cellular pathways that were regulated by nspl1: histonerelated proteins, cell cycle and DNA replication pathways, MAPK signaling pathways, ubiquitin-proteasome pathways, and complementary pathways (Table 1 ).

For validation of the fold changes in the gene expression profiles, five genes (TNFSF10, DEPTOR, SH2, NOL6, and EGR1) were chosen according to their fold changes, and RT-qPCR was conducted. NOL6 and EGR1 were chosen to represent the group of upregulated genes, and TNFSF10 and DEPTOR were chosen to represent the group of downregulated genes, while $\mathrm{SH} 2$ was chosen as an unregulated gene. The results from RT-qPCR for these genes were in good agreement with their fold changes in the microarray and confirmed the fold change profiles for differential gene expression (Figure 3).

3.4. Regulation of Histone-Related Functions, Complement, MAPK Signaling, and Proteasome Pathways. Seventeen histone-related genes were found to be upregulated, whereas three genes (C1S, C1R, and C3) in the complement system were downregulated (Table 1). C1S and C1R were responsible for the activation of the classic pathway of the complement 


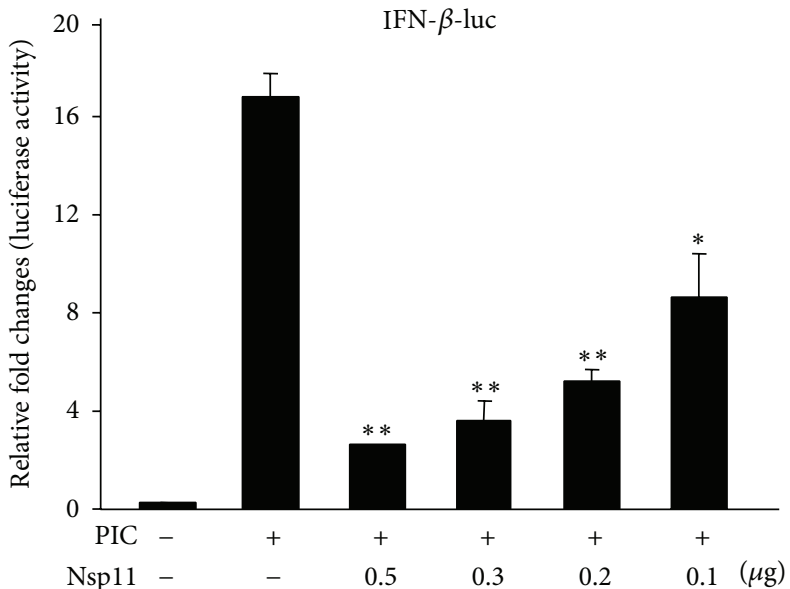

(a)

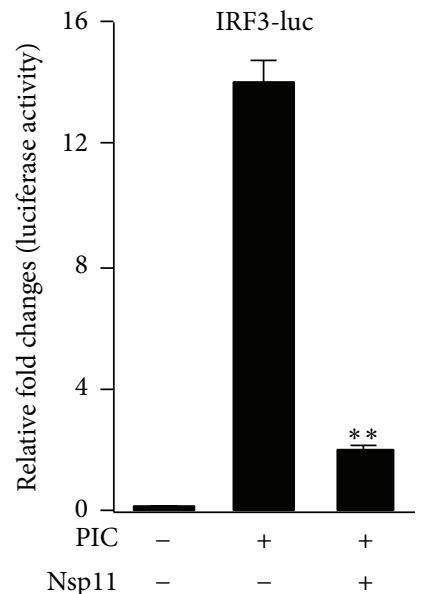

(b)

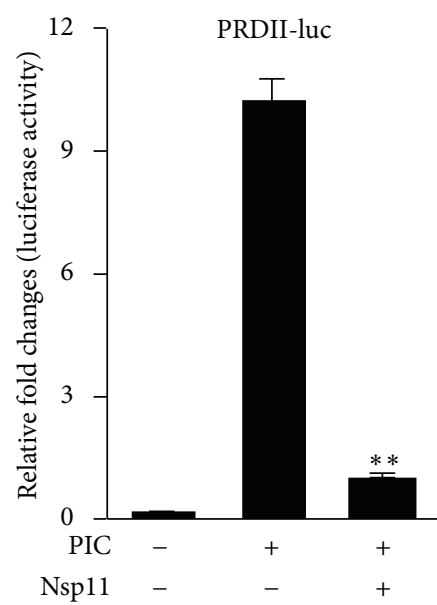

(c)

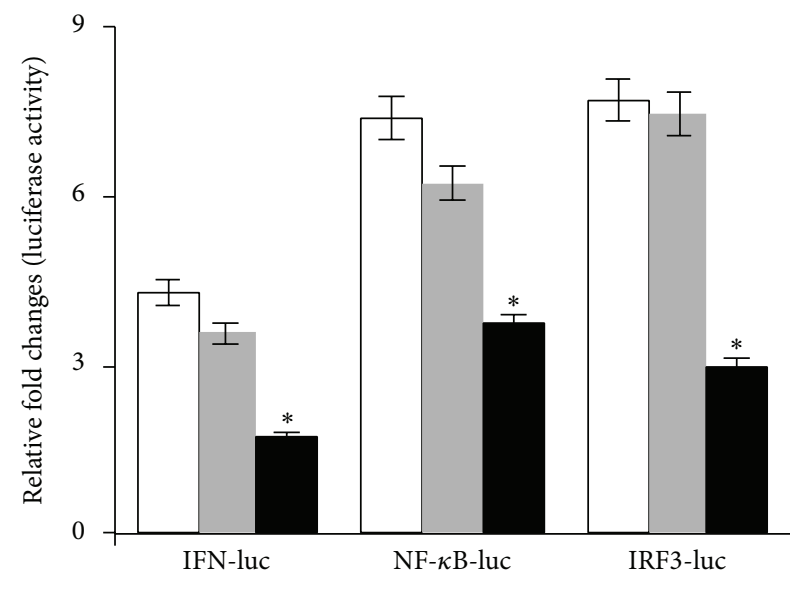

(d)

FIGURE 2: Suppression of type I IFN induction by PRRSV nspll in gene-transfected MARC-145 cells ( $a$, b, and c), and stably-expressing MARC-nsp11 cells (d). (a) MARC-145 cells were seeded in 12-well plates and transfected with pXJ41 (0.5 $\mu$ g) or pXJ41-Flag-nsp11 plasmid of $0.5,0.3,0.2$, or $0.1 \mu \mathrm{g}$, together with pRL-TK $(0.05 \mu \mathrm{g})$ and pIFN- $\beta$-luc $(0.5 \mu \mathrm{g})$ reporter. After $24 \mathrm{~h}$, cells were transfected with $0.5 \mu \mathrm{g} / \mathrm{mL}$ of poly (I:C) for $16 \mathrm{~h}$ and harvested for luciferase assay (Promega). (b) and (c) MARC-145 cells were cotransfected with either pIRF3-luc (0.5 $\mu$ g) or pPRDII-luc $(0.5 \mu \mathrm{g})$ or pXJ41-Flag-nsp11 $(0.5 \mu \mathrm{g})$ or pXJ41 $(0.5 \mu \mathrm{g})$, along with pRL-TK. After $24 \mathrm{~h}$, cells were transfected with $0.5 \mu \mathrm{g} / \mathrm{mL}$ of poly (I:C) for $16 \mathrm{~h}$ and harvested for luciferase assay (Promega). The experiments were conducted in duplicate and repeated three times, and the overage values were depicted. The fold change was calculated by (PIC+)/(PIC-) for each sample. The negative control represents the basal level luciferase activity. The values from nspll gene-transfected samples were compared with those of poly (I:C) stimulation, and the data were analyzed using 2 -tail $t$-test. One star $(*)$ represents $P<0.01$ and two stars $(* *)$ represent $P<0.005$. (d) MARC-145 or MARC-nsp11 cells were cotransfected with pIFN- $\beta$-luc, pIRF3-luc, or pPRDII-luc and pRL-TK. MARC-145 cells were transfected with the pLNCX2 empty vector as a negative control. All samples were treated and processed as described above. Luciferase assays were conducted in duplicate and repeated three times. One star $(*)$ represents $P<0.05$. White bars represent MARC-145 cells, grey bars represent the pLNCX2 retrovirus expression vector-transfected MARC-145 cells, and black bars represent MARC-nspll cells.

system. C1R is autoactivated and then cleaves $\mathrm{C} 1 \mathrm{~S}$ for activation. Activated C1S cleaves $\mathrm{C} 4$ and $\mathrm{C} 2$, resulting in the activation of C3-convertase complex [28]. C3 is a central molecule in the complement system whose activation is essential for all the important functions performed by this system [29]. The downregulation of C1S, C1R, and C3 suggests the possible suppression of the complement system by nsp11.

Six genes (DUSP1, DUSP6, FOS, MYC, JUN, and SRF) related to the MAPK signaling pathways were found to be upregulated, and five genes in the proteasome pathways were found to be regulated, among which SUMO1 and SNCA were downregulated and PSMD3, PSMB10, and PSMA7 were upregulated (Table 1). DUSPs regulate the cellular localization and activity of MAPK which functions in the negative feedback loop of ERK regulation [30]. DUSP1 dephosphorylates ERK in the nucleus and allows its trafficking to the cytoplasm [31], while DUSP6 causes the cytoplasmic retention of ERK2 [31]. C-Jun/AP-1 and c-Fos genes were also upregulated in our study, which can be activated by JNK and p38 MAPK [32]. For the proteasome pathways, three (PSMD3, PSMB10, and PSMA7) out of five are proteasome subunits, and their 
TABLE 1: Five major cellular pathways regulated by PRRSV nsp11.

\begin{tabular}{|c|c|c|c|c|c|}
\hline Pathway & Gene & Gene assignment & Transcript cluster ID & GenBank number & Fold change \\
\hline \multirow{17}{*}{$\begin{array}{l}\text { Histone-related } \\
\text { functions }\end{array}$} & HIST2H3D & Histone cluster 2, H3d & 7919589 & NM_001123375 & 2.48 \\
\hline & HIST1H2AI & Histone cluster 1, H2ai & 8117580 & NM_003509 & 2.69 \\
\hline & HIST1H2BH & Histone cluster $1, \mathrm{H} 2 \mathrm{bh}$ & 8117426 & NM_003524 & 2.31 \\
\hline & HIST1H2AK & Histone cluster 1, H2ak & 8124524 & NM_003510 & 3.66 \\
\hline & HIST1H2BK & Histone cluster 1, H2bk & 8068898 & NM_080593 & 1.98 \\
\hline & HIST1H2AI & Histone cluster 1, H2ai & 8117583 & NM_003509 & 2.31 \\
\hline & HIST1H4I & Histone cluster $1, \mathrm{H} 4 \mathrm{i}$ & 8117537 & NM_003495 & 1.84 \\
\hline & HIST1H2BM & Histone cluster 1, H2bm & 8117594 & NM_003521 & 2.13 \\
\hline & HIST2H2AA3 & Histone cluster 2, H2aa3 & 7905079 & NM_003516 & 1.94 \\
\hline & HIST2H3A & Histone cluster 2, H3a & 7905085 & NM_001005464 & 2.60 \\
\hline & HIST1H2AH & Histone cluster $1, \mathrm{H} 2 \mathrm{ah}$ & 8117543 & NM_080596 & 2.83 \\
\hline & HIST2H2BE & Histone cluster 2, H2be & 7919637 & NM_003528 & 2.06 \\
\hline & HIST1H3A & Histone cluster 1, H3a & 8117330 & NM_003529 & 2.00 \\
\hline & HIST1H3F & Histone cluster 1, H3f & 8124437 & NM_021018 & 3.81 \\
\hline & HIST1H2BB & Histone cluster $1, \mathrm{H} 2 \mathrm{bb}$ & 8124394 & NM_021062 & 2.14 \\
\hline & HIST1H2BI & Histone cluster 1, H2bi & 8117429 & NM_003525 & 1.95 \\
\hline & HIST1H3G & Histone cluster 1, H3g & 8124440 & NM_003534 & 2.95 \\
\hline \multirow{3}{*}{ Complement pathway } & $\mathrm{C} 1 \mathrm{~S}$ & $\begin{array}{l}\text { Complement component } 1, \mathrm{~s} \\
\text { subcomponent }\end{array}$ & 7953603 & NM_201442 & -2.93 \\
\hline & $\mathrm{C} 1 \mathrm{R}$ & $\begin{array}{l}\text { Complement component } 1, \mathrm{r} \\
\text { subcomponent }\end{array}$ & 7960744 & NM_001733 & -1.93 \\
\hline & C3 & Complement component 3 & 8033257 & NM_000064 & -2.19 \\
\hline \multirow{6}{*}{$\begin{array}{l}\text { MAPK signaling } \\
\text { pathway }\end{array}$} & DUSP1 & Dual specificity phosphatase 1 & 8115831 & NM_004417 & 2.96 \\
\hline & FOS & $\begin{array}{l}\text { FBJ murine osteosarcoma viral } \\
\text { oncogene homolog }\end{array}$ & 7975779 & NM_005252 & 6.42 \\
\hline & MYC & $\begin{array}{l}\text { V-myc myelocytomatosis viral } \\
\text { oncogene homolog }\end{array}$ & 8148317 & NM_002467 & 1.96 \\
\hline & JUN & Jun protooncogene & 7916609 & NM_002228 & 2.02 \\
\hline & DUSP6 & Dual specificity phosphatase 6 & 7965335 & NM_001946 & 2.81 \\
\hline & SRF & $\begin{array}{l}\text { Serum response factor (c-fos serum } \\
\text { response element-binding } \\
\text { transcription factor) }\end{array}$ & 8119712 & NM_003131 & 1.83 \\
\hline \multirow{5}{*}{ Proteasomal pathway } & SUMO1 & $\begin{array}{l}\text { SMT3 suppressor of mif two } 3 \\
\text { homolog } 1\end{array}$ & 8058335 & NM_003352 & -1.62 \\
\hline & SNCA & $\begin{array}{l}\text { Synuclein, alpha (non-A4 } \\
\text { component of amyloid precursor) }\end{array}$ & 8101762 & NM_000345 & -2.14 \\
\hline & PSMD3 & $\begin{array}{l}\text { Proteasome (prosome, macropain) } \\
26 \mathrm{~S} \text { subunit, non-ATPase, } 3\end{array}$ & 8006984 & NM_002809 & 1.74 \\
\hline & PSMB10 & $\begin{array}{l}\text { Proteasome (prosome, macropain) } \\
\text { subunit, beta type, } 10\end{array}$ & 8002133 & NM_002801 & 1.82 \\
\hline & PSMA7 & $\begin{array}{l}\text { Proteasome (prosome, macropain) } \\
\text { subunit, alpha type, } 7\end{array}$ & 8067382 & NM_002792 & 1.81 \\
\hline
\end{tabular}


TABle 1: Continued.

\begin{tabular}{|c|c|c|c|c|c|}
\hline Pathway & Gene & Gene assignment & Transcript cluster ID & GenBank number & Fold change \\
\hline \multirow{3}{*}{ DNA replication } & MCM5 & $\begin{array}{l}\text { Minichromosome maintenance } \\
\text { complex component } 5\end{array}$ & 8072687 & NM_006739 & 2.05 \\
\hline & $\mathrm{MCM} 4$ & $\begin{array}{l}\text { Minichromosome maintenance } \\
\text { complex component } 4\end{array}$ & 8146357 & NM_005914 & 2.11 \\
\hline & MCM2 & $\begin{array}{l}\text { Minichromosome maintenance } \\
\text { complex component } 2\end{array}$ & 8082350 & NM_004526 & 1.94 \\
\hline \multirow{4}{*}{ Cell cycle } & CDC25A & $\begin{array}{l}\text { Homo sapiens cell division cycle } 25 \\
\text { homolog A }\end{array}$ & 8086880 & NM_001789 & 2.12 \\
\hline & CDC45 & Cell division cycle 45 homolog & 8071212 & NM_001178010 & 2.00 \\
\hline & MYC & $\begin{array}{l}\text { Homo sapiens v-myc } \\
\text { myelocytomatosis viral oncogene } \\
\text { homolog }\end{array}$ & 8148317 & NM_002467 & 1.96 \\
\hline & ORC1 & $\begin{array}{l}\text { Origin recognition complex, } \\
\text { subunit } 1\end{array}$ & 7916167 & NM_004153 & 1.73 \\
\hline
\end{tabular}

TABLE 2: Primer sequences for RT-qPCR for selected genes.

\begin{tabular}{ll}
\hline Primer & Primer sequence \\
\hline TNFSF10-F & $5^{\prime}$-AAGTGGCATTGCTTGTTTCT-3' \\
TNFSF10-R & $5^{\prime}$-TTGATGATTCCCAGGAGTTTA-3' \\
DEPTOR-F & $5^{\prime}$-TTTTGTGGTGCGAGGAAGTAAGC-3' \\
DEPTOR-R & $5^{\prime}$-GCAGGACATTGAGCCCGTTG-3' \\
NOL6-F & $5^{\prime}$-AACCGAGGACAGGAAAGGATTG-3' \\
NOL6-R & $5^{\prime}$-TGTAGACCAGACTGAAAGGAGGC-3' \\
SH2-F & $5^{\prime}$-TCTGTGAGTTTGAAGCCCTGAG-3' \\
SH2-R & $5^{\prime}$-GCAATGTTTATCATCCCACCC-3 \\
EGR1-F & $5^{\prime}$-AGCGATGAACGCAAGAGGCA-3' \\
EGR1-R & $5^{\prime}$-GGATGGGTATGAGGTGGTGGC-3' \\
GAPDH-F & $5^{\prime}$-CGGAGTCAACGGATTTGGTCGTA-3' \\
GAPDH-R & $5^{\prime}$-AGCCTTCTCCATGGTGGTGAAGAC-3' \\
\hline
\end{tabular}

upregulation suggests an enhanced effect on the proteasomal pathways by nsp11. SUMO1 (small ubiquitin-like modifier 1) has multiple functions by attaching itself to substrates referred to as sumoylation. After sumoylation, protein may undergo degradation through the proteasome $[33,34]$.

3.5. Delay of Cell Cycle by nsp11. The microarray data suggested the regulation of cell cycle and DNA replication pathways by nsp11. A total of 10 genes related to these pathways were found to be regulated (Table 1). Among these, cell division cycle 45 (CDC45)-like and CDC25 homolog A are proteins controlling the cell cycle progression [35-37], whereas minichromosome maintenance complex 2 (MCM2), MCM4, and MCM5 are helicase components regulating DNA replication [38].

The MCM2-7 complex is assembled on the eukaryotic chromosomes during the G1 phase of a cell cycle, which is then activated during the S phase by MCM10, CDC45, and the GINS complex [39]. The regulation of MCMs and CDC genes suggests that nsp11 may perturb the normal host cell cycle. To examine this possibility, identical numbers of MARC-nsp11 cells and MARC-145 cells were seeded on plates, and $24 \mathrm{~h}$ later cells were collected for DNA staining and flow cytometry. In two independent experiments, the MARC-nsp11 cells at the $S$ phase constituted $28.5 \%$ (Figure $4(\mathrm{~b})$ ) as compared to $12.6 \%$ for MARC-145 cells (Figure 4(a)), which was more than a 2-fold increase for nspll-expressing cells indicating that MARC-nspll cells were accumulating at the S phase by $24 \mathrm{~h}$.

To examine the nature of DNA accumulation at the $S$ phase by nsp11, cells were pulsed-labeled for $10 \mathrm{~min}, 20 \mathrm{~min}$, or $24 \mathrm{~h}$ with BrdU and stained for BrdU incorporation and lamins. BrdU is a nucleotide analog and thus can be incorporated into replicating DNA, whereas lamin proteins are major architectural proteins of the nuclear lining inside the nuclear membrane in cells. Thus, all cells are anticipated to be stained with an anti-lamin antibody, whereas only cells synthesizing new DNA in the $S$ phase are presumed to be stained with an anti-BrdU antibody. A short pulse of $10 \mathrm{~min}$ or 20 min would detect BrdU incorporation in a single cell cycle, whereas a longer time incubation of $24 \mathrm{~h}$ would detect multiple cell cycles and thus the majority of normal cells would be positive for BrdU staining (Figure 5(a)). A total of 200 lamin-positive cells (in red) were randomly chosen for each slide, and BrdU positive cells (in green) out of the lamin-positive cells were counted to determine BrdU incorporation rates using the formula described in Materials and Methods. MARC-nsp11 cells exhibited less numbers of BrdU-positive cells after the $10 \mathrm{~min}$ and $20 \mathrm{~min}$ pulses compared to those of MARC-145 cells (Figure 5(a)), and their BrdU incorporation rates dropped from $47.07 \%$ (white bar) to $38.07 \%$ (black bar) $(P<0.005)$ and from $57.8 \%$ (white bar) to $44 \%$ (black bar) $(P<0.005)$, respectively (Figure 5(b)). After $24 \mathrm{~h}$ of labeling, a greater reduction of BrdU staining was observed for MARC-nspll cells, where the percentage of BrdU incorporation decreased from 92\% (while bar) to 49.73\% (black bar) $(P<0.001$; Figure 5(b)). The intensity of BrdU staining in MARC-nspll cells was also significantly reduced after the $24 \mathrm{~h}$ pulse compared to that of MARC-145 cells (Figure 5(a)), demonstrating the substantial suppression of DNA synthesis by nsp11. Both flow cytometry and BrdU 


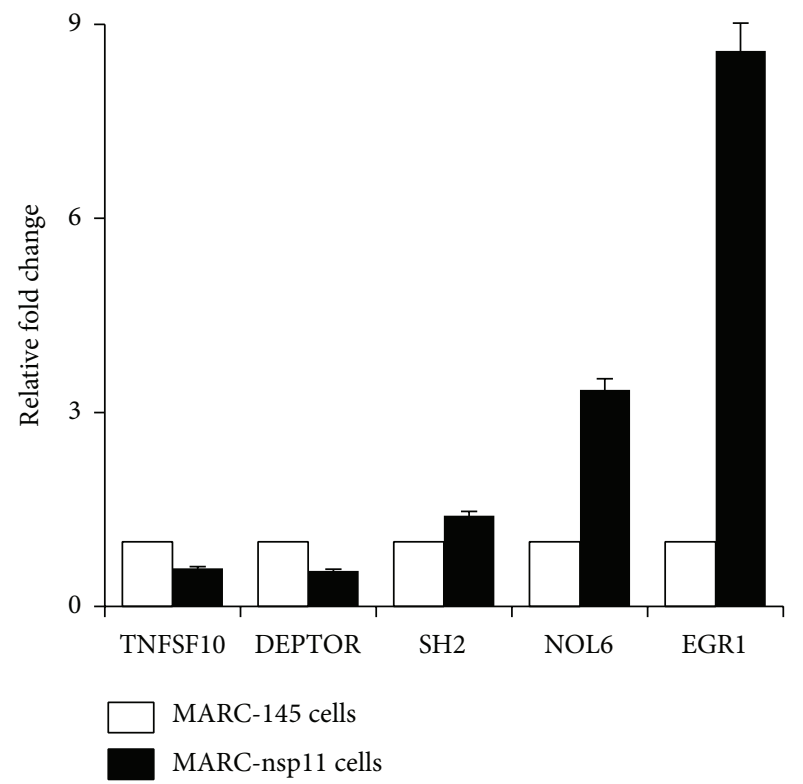

\begin{tabular}{|c|c|c|}
\hline Gene & $\begin{array}{c}\text { Microarray } \\
\text { fold change }\end{array}$ & $\begin{array}{c}\text { Real-time } \\
\text { PCR fold } \\
\text { change }\end{array}$ \\
\hline TNFSF10 & -4.5 & -1.74 \\
\hline DEPTOR & -5.98 & -1.85 \\
\hline SH2 & $< \pm 2$ & 1.4 \\
\hline NOL6 & +2.89 & 3.35 \\
\hline EGR1 & +11.6 & 8.59 \\
\hline
\end{tabular}

Figure 3: Confirmation of differential gene expression by RT-qPCR in MARC-nspll cells. The same preparations that were used for RNA microarray were used for RT-qPCR. For quantitative PCR, two genes (NOL6 and EGR1) were chosen to represent upregulated genes by nsp11, and TNFSF10 and DEPTOR were chosen as the downregulated genes in the microarray assays (Table 2). SH2 was chosen as a nonregulated gene. Bars illustrate the differential gene expression determined by RT-qPCR. White bars represent MARC-145 cells and black bars indicate MARC-nspll cells. Numbers in the table show the fold changes.

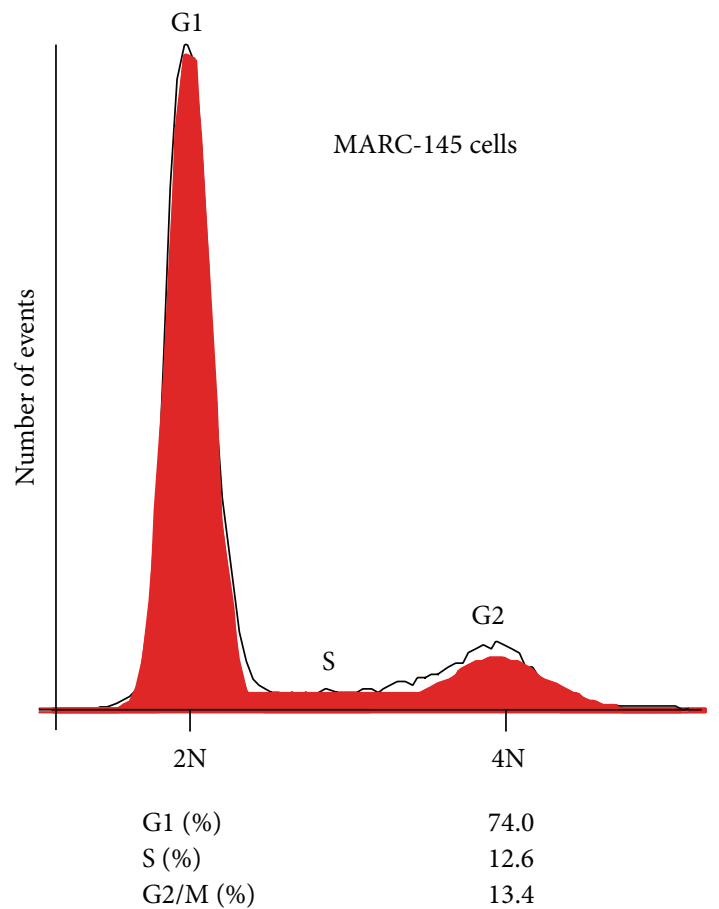

(a)

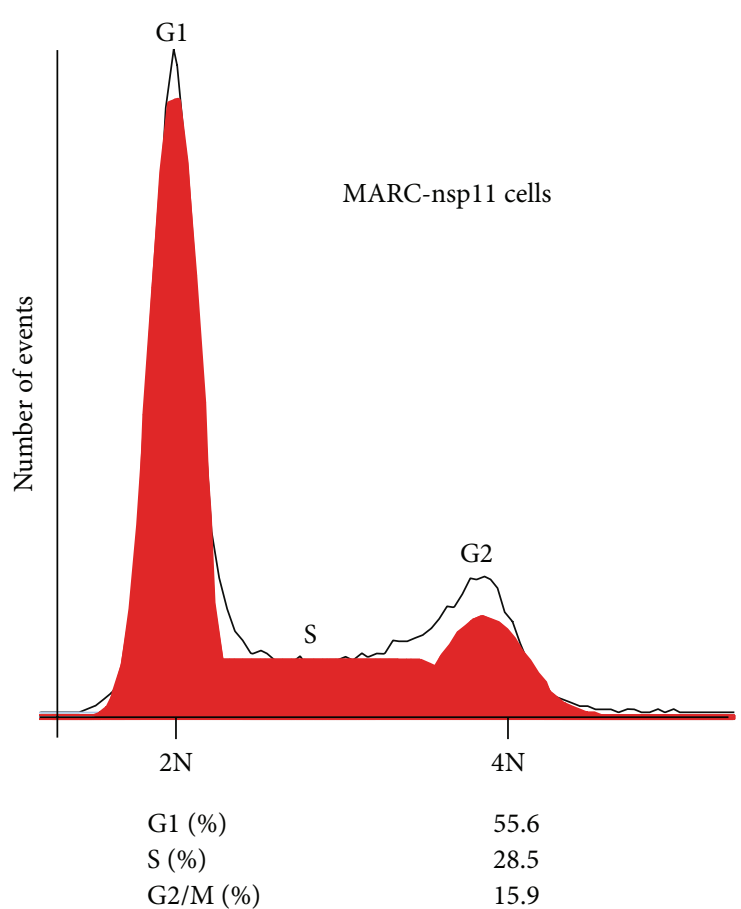

(b)

FIGURE 4: Flow cytometric analysis for MARC-nspll cells. A total of $1 \times 10^{6}$ MARC-145 or MARC-nspll cells were seeded in 60 mm-diameter dishes and cultivated for $24 \mathrm{~h}$. Cells were gently harvested by trypsinization and fixed with cold ethanol. Cells were stained with $10 \mu \mathrm{g} / \mathrm{mL}$ of propidium iodide (PI) and subjected to flow cytometry. Shown is the PI trace (red areas) indicating the proportion of cells with the $2 \mathrm{~N}$ and $4 \mathrm{~N}$ DNA contents. The red areas present relative percentages. G1, first gap period; G2, second gap period; S, DNA synthesis and chromosome replication. 


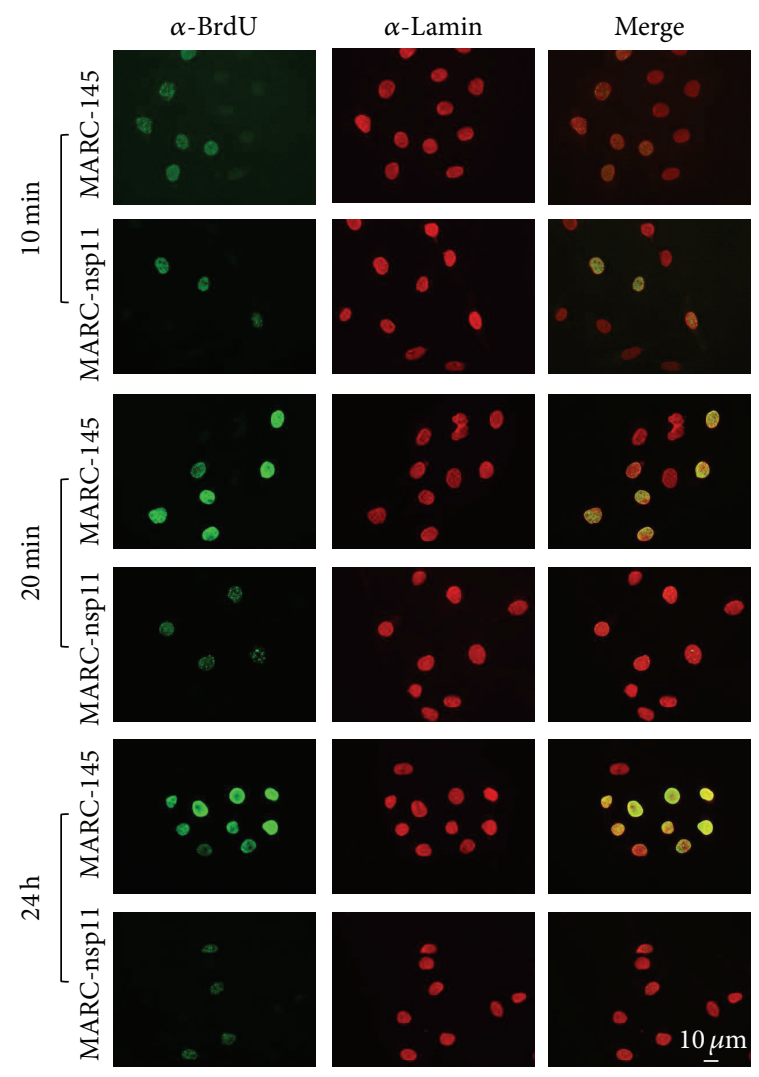

(a)

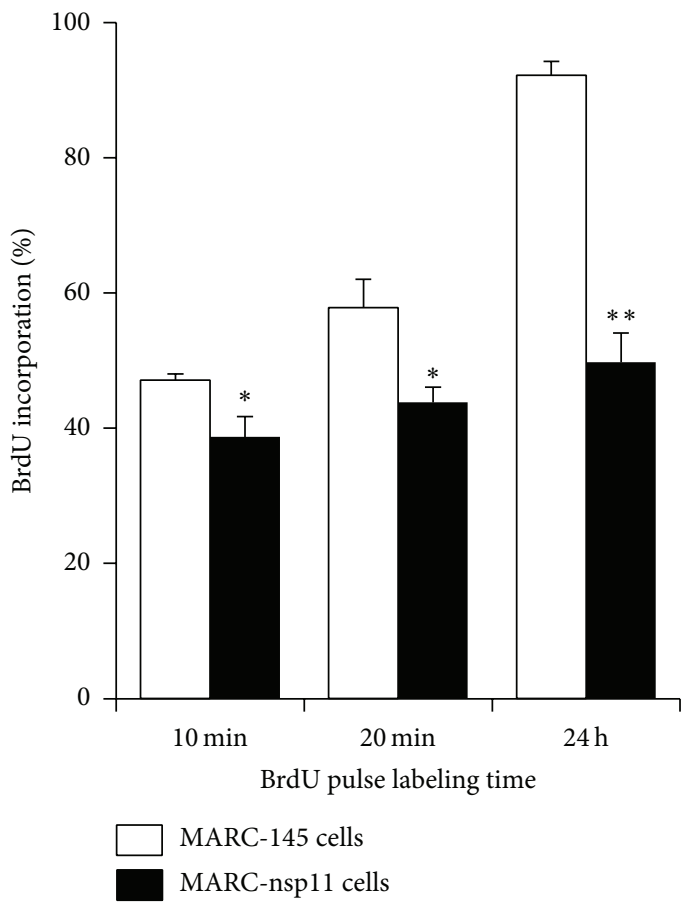

(b)

FIGURE 5: BrdU incorporation and DNA synthesis in MARC-nspll cells. (a) Cells were labeled with BrdU and stained to determine the newly synthesized cellular DNA at the S phase. Cells were pulse-labeled with $10 \mu \mathrm{M}$ of BrdU for $10 \mathrm{~min}$ and $20 \mathrm{~min}$, or $100 \mathrm{nM}$ for $24 \mathrm{~h}$. Cells were fixed with $2 \%$ paraformaldehyde for $15 \mathrm{~min}$ and permeabilized with $0.5 \%$ Triton X-100 followed by staining with an anti-lamin antibody (shown in the red color). Cells were then incubated with $4 \mathrm{~N} \mathrm{HCl}$ to denature the DNA, and stained for DNA-incorporated BrdU using an anti-BrdU antibody (shown in the green color). The scale bar in white indicates 10 micron. (b) BrdU incorporation rates in MARC-nspll cells. A total of 200 lamin-positive cells were counted, and of the 200 cells BrdU-positive cells were counted. The BrdU incorporation rates were then calculated using the following formula: (number of double-positive cells for BrdU and lamin) $/(200$ lamin-positive cells) $\times 100$. The experiments were repeated 4 times and the results were presented as the arithmetic means \pm standard error $(n=4)$. One star $(*)$ represents $P<0.005$ and two stars $(* *)$ represent $P<0.001$. MARC-145 cells are indicated in unfilled white bars and MARC-nspll cells are indicated in black bars.

staining data indicate that nspll slows down the cell cycle progression through the $\mathrm{S}$ phase.

\section{Discussion}

In the present study, MARC-nsp1l cells were established to constitutively express PRRSV nsp11, and an RNA microarray was conducted in these cells to study differential transcription responses to nspll. The microarray studies identified 170 differentially regulated cellular genes with the threshold of 2. Of these, 104 genes were downregulated and 66 genes were upregulated, and many of these genes were able to be placed according to their functional relevance into 5 different pathways: histone-related proteins, cell cycle and DNA replication, MAPK signaling, ubiquitin-proteasome, and the complement system. Compared to previous studies $[19,20]$, the genes identified in our study were fewer in number and less in diverse. This is probably because the regulated genes identified in our study were exclusively nsp11specific, whereas the genes in the previous studies were responders to the entire spectrum of viral proteins. Thus, nspl1-regulated genes were mostly included in the previously identified genes. Zhou et al. [20] also showed that the genes relevant to cell cycle and DNA replication were regulated by highly pathogenic (HP)-PRRSV in PAMs. Chromosome organizing proteins were also regulated by nspll, and proteins regulating the complement system for tissue remolding and inflammation were also found in our study. c-Jun and c-Fos are two effectors of the MAPK signaling pathway, and they were specifically upregulated during PRRSV infection [19]. PRRSV-mediated activation of the MAPK signaling pathway and the increase of JNK and p38 phosphorylation have recently been demonstrated [40], which is also in support of our findings.

Of the possible pathways regulated by nsp11, the cell cycle pathway was chosen and explored further. It appears that the cell cycle progression was delayed at the $S$ phase 
in nsp11-expressing cells compared to MARC-145 cells. A similar observation was recently made for coronavirus in cells expressing nsp15, which is a coronavirus homolog of PRRSV nsp11 [41]. In that study, SARS-CoV nsp15 was shown to downregulate the retinoblastoma $(\mathrm{Rb})$ activity which is responsible for cell proliferation. As a consequence, a higher percentage of cells was accumulating at the $S$ phase when expressing nsp15, supporting our observation of slower cell cycle progression in nspll-expressing cells. The $S$ phase tardiness may be associated with an altered DNA replication, since several MCM proteins, which are components of DNA helicase, were upregulated (Table 1). It is possible that the increase of helicase proteins might have caused a malfunction of the replication fork and thus the inhibition of DNA synthesis in MARC-nsp11 cells.

Virus-mediated cell cycle regulation is not uncommon and can be beneficial to viruses. In particular, it is true for DNA viruses replicating in the nucleus such as SV40, herpes simplex virus, and adeno-associated virus, in which by arresting the cell cycle of infected cells, the cellular DNA replicative machinery may be captured and utilized for viral DNA replication [42-44]. For RNA viruses, influenza virus replication has been shown to be regulated by helicase and the MCM complex consisting of MCM2-7 [45]. The interaction between the influenza virus PA polymerase and MCM complex increases the stability of RNA polymerase. In our study, MCM2, MCM4, and MCM5 were upregulated by nspll. Even though the PRRSV replicates in the cytoplasm, the cell cycle regulation may be considered beneficial for the virus, since an available pool of cellular machineries can be maximally utilized towards the production of progeny at an early stage of infection. For PRRSV, nucleocapsid (N) protein has also been suggested to regulate the cell cycle progression by modulating the ribosomal RNA synthesis in the nucleolus [46]. Thus, it is possible that $\mathrm{N}$ and nsp11 may both regulate the cell cycle progression and facilitate virus production by targeting different cellular components modulating the host cell cycle. The $\mathrm{N}$ protein is an RNA-binding protein which contains the nuclear localization signal (NLS) and thus localizes in the nucleus and nucleolus. By yeast 2-hybrid screening, the inhibitor of MyoD family a (I-mfa) domaincontaining protein was identified interacting with PRRSV $\mathrm{N}$ [47]. Since the I-mfa domain-containing protein interacts with cyclin T1 [48], which participates in the control of the cell cycle, this interaction suggests a regulatory role of $\mathrm{N}$ for the cell cycle [17]. Different from N, nspll resides in the cytoplasm and contains an endoribonuclease activity. Nsp11 may alter the function or expression of cytoplasmic cellular components such as mRNA modification, which may then result in the regulation of the cell cycle. Indeed, modification of cellular mRNA by nsp11 has been suggested previously [49]. In summary, our data show that the PRRSV nspl1 protein is responsible for the delay of the $S$ phase and thus, together with $\mathrm{N}$, may regulate the cell cycle progression. $\mathrm{N}$ functions in the nucleus and nspll functions in the cytoplasm.

In the current study, only a few immune-related cytokine genes were identified especially for IFN-related genes. This is probably due to the cell type and the treatments used in our study. MARC-145 cells are epithelial cells of the African green monkey kidney, and these cells are anticipated to produce only a minimal amount of cytokines, and their ability to produce IFN is limited unless they are stimulated. A study is in progress to compare the gene expression profiles in MARC-nspll cells before and after stimulation.

The microarray study allowed us to identify differential effects of the nsp11 protein on the cellular gene expression profiles. Studies are required to verify the significance of the differentially regulated gene expression. Analyses of relative protein modifications and activations especially for checkpoint proteins will help us understand the basis of the change of S phase caused by nsp11. Clearly, our data provide new insights into the understanding of cell-virus interactions and the pathogenic mechanisms of PRRSV and host responses to infection.

\section{Conflict of Interests}

The authors declare that there is no conflict of interests regarding the publication of this paper.

\section{Acknowledgments}

This study was supported by funding provided to Dongwan Yoo by Agriculture and Food Research Initiative (AFRI) Competitive (Grant nos. 2008-35204-04634 and 2013-6701521243), from the US Department of Agriculture (USDA), National Institute of Food and Agriculture, the USDA Hatch Funds, the USDA Multistate Research Funds of Agricultural Experiment Stations, and the US National Pork Board. Sumanprava Giri is a NSF-CMMB-IGERT fellow, and Supriya G. Prasanth is supported by NSF award 0843604, NIH RO1 GM099669, and NSF Career 1243372.

\section{References}

[1] E. J. Neumann, J. B. Kliebenstein, C. D. Johnson et al., "Assessment of the economic impact of porcine reproductive and respiratory syndrome on swine production in the United States," Journal of the American Veterinary Medical Association, vol. 227, no. 3, pp. 385-392, 2005.

[2] A. M. Q. King, M. J. Adams, E. B. Carstens, and E. J. Lefkovitz, Virus Taxonomy Ninth International Report of the International Committee on Taxonomy of Viruses, Elsevier Academic Press, 2012.

[3] K. K. Conzelmann, N. Visser, P. van Woensel, and H. J. Thiel, "Molecular characterization of porcine reproductive and respiratory syndrome virus, a member of the arterivirus group," Virology, vol. 193, no. 1, pp. 329-339, 1993.

[4] A. E. Gorbalenya, L. Enjuanes, J. Ziebuhr, and E. J. Snijder, "Nidovirales: evolving the largest RNA virus genome," Virus Research, vol. 117, no. 1, pp. 17-37, 2006.

[5] J. J. M. Meulenberg, M. M. Hulst, E. J. de Meijer et al., "Lelystad virus, the causative agent of porcine epidemic abortion and respiratory syndrome (PEARS), is related to LDV and EAV," Virology, vol. 192, no. 1, pp. 62-72, 1993.

[6] E. J. Snijder, “The arterivirus replicase: the road from RNA to protein(s), and back again," Advances in Experimental Medicine and Biology, vol. 440, pp. 97-108, 1998. 
[7] R. Allende, T. L. Lewis, Z. Lu et al., "North American and European porcine reproductive and respiratory syndrome viruses differ in non-structural protein coding regions," Journal of General Virology, vol. 80, no. 2, pp. 307-315, 1999.

[8] C. J. Nelsen, M. P. Murtaugh, and K. S. Faaberg, "Porcine reproductive and respiratory syndrome virus comparison: divergent evolution on two continents," Journal of Virology, vol. 73, no. 1, pp. 270-280, 1999.

[9] A. E. Firth, J. C. Zevenhoven-Dobbe, N. M. Wills et al., "Discovery of a small arterivirus gene that overlaps the gp5 coding sequence and is important for virus production," Journal of General Virology, vol. 92, no. 5, pp. 1097-1106, 2011.

[10] C. R. Johnson, T. F. Griggs, J. Gnanandarajah, and M. P. Murtaugh, "Novel structural protein in porcine reproductive and respiratory syndrome virus encoded by an alternative orf5 present in all arteriviruses," Journal of General Virology, vol. 92, no. 5, pp. 1107-1116, 2011.

[11] J. A. den Boon, E. J. Snijder, E. D. Chirnside, A. A. F. de Vries, M. C. Horzinek, and W. J. M. Spaan, "Equine arteritis virus is not a togavirus but belongs to the coronaviruslike superfamily," Journal of Virology, vol. 65, no. 6, pp. 2910-2920, 1991.

[12] Y. Fang and E. J. Snijder, "The PRRSV replicase: exploring the multifunctionality of an intriguing set of nonstructural proteins," Virus Research, vol. 154, no. 1-2, pp. 61-76, 2010.

[13] S. Wootton, D. Yoo, and D. Rogan, "Full-length sequence of a Canadian porcine reproductive and respiratory syndrome virus (PRRSV) isolate," Archives of Virology, vol. 145, no. 11, pp. 22972323, 2000.

[14] K. A. Ivanov, T. Hertzig, M. Rozanov et al., "Major genetic marker of nidoviruses encodes a replicative endoribonuclease," Proceedings of the National Academy of Sciences of the United States of America, vol. 101, no. 34, pp. 12694-12699, 2004.

[15] D. D. Nedialkova, R. Ulferts, E. van den Born et al., "Biochemical characterization of arterivirus nonstructural protein 11 reveals the nidovirus-wide conservation of a replicative endoribonuclease," Journal of Virology, vol. 83, no. 11, pp. 5671-5682, 2009.

[16] C. C. Posthuma, D. D. Nedialkova, J. C. Zevenhoven-Dobbe, J. H. Blokhuis, A. E. Gorbalenya, and E. J. Snijder, "Site-directed mutagenesis of the nidovirus replicative endoribonuclease NendoU exerts pleiotropic effects on the arterivirus life cycle," Journal of Virology, vol. 80, no. 4, pp. 1653-1661, 2006.

[17] D. Yoo, C. Song, Y. Sun, Y. Du, O. Kim, and H. C. Liu, "Modulation of host cell responses and evasion strategies for porcine reproductive and respiratory syndrome virus," Virus Research, vol. 154, no. 1-2, pp. 48-60, 2010.

[18] L. K. Beura, S. N. Sarkar, B. Kwon et al., "Porcine reproductive and respiratory syndrome virus nonstructural protein $1 \beta$ modulates host innate immune response by antagonizing IRF3 activation," Journal of Virology, vol. 84, no. 3, pp. 1574-1584, 2010.

[19] S. Xiao, D. Mo, Q. Wang et al., "Aberrant host immune response induced by highly virulent PRRSV identified by digital gene expression tag profiling," BMC Genomics, vol. 11, no. 1, article 544, 2010.

[20] P. Zhou, S. Zhai, X. Zhou et al., "Molecular characterization of transcriptome-wide interactions between highly pathogenic porcine reproductive and respiratory syndrome virus and porcine alveolar macrophages in vivo," International Journal of Biological Sciences, vol. 7, no. 7, pp. 947-959, 2011.

[21] H. S. Kim, J. Kwang, I. J. Yoon, H. S. Joo, and M. L. Frey, "Enhanced replication of porcine reproductive and respiratory syndrome (PRRS) virus in a homogeneous subpopulation of MA-104 [MA104] cell line," Archives of Virology, vol. 133, no. 3-4, pp. 477-483, 1993.

[22] R. C. Gentleman, V. J. Carey, D. M. Bates et al., "Bioconductor: open software development for computational biology and bioinformatics," Genome Biology, vol. 5, no. 10, article R80, 2004.

[23] R. A. Irizarry, B. Hobbs, F. Collin et al., "Exploration, normalization, and summaries of high density oligonucleotide array probe level data," Biostatistics, vol. 4, no. 2, pp. 249-264, 2003.

[24] G. K. Smyth, "Linear models and empirical bayes methods for assessing differential expression in microarray experiments," Statistical Applications in Genetics and Molecular Biology, vol. 3, no. 1, article 3, 2004.

[25] G. K. Smyth, R. Gentleman, V. Carey, S. Dudoit, R. Irizarry, and W. Huber, "Limma: linear models for microarray data," in Bioinformatics and Computational Biology Solutions Using $R$ and Bioconductor, pp. 397-420, Springer, New York, NY, USA, 2005.

[26] Y. Benjamini and Y. Hochberg, "Controlling the false discovery rate: a practical and powerful approach to multiple testing," Journal of the Royal Statistical Society B, vol. 57, pp. 289-300, 1995.

[27] K. Bhardwaj, L. Guarino, and C. C. Kao, "The severe acute respiratory syndrome coronavirus Nsp15 protein is an endoribonuclease that prefers manganese as a cofactor," Journal of Virology, vol. 78, no. 22, pp. 12218-12224, 2004.

[28] P. Gál, J. Dobó, P. Závodszky, and R. B. M. Sim, “Early complement proteases: C1r, C1s and MASPs. A structural insight into activation and functions," Molecular Immunology, vol. 46, no. 14, pp. 2745-2752, 2009.

[29] A. Sahu and J. D. Lambris, "Structure and biology of complement protein C3, a connecting link between innate and acquired immunity," Immunological Reviews, vol. 180, pp. 35-48, 2001.

[30] K. L. Jeffrey, M. Camps, C. Rommel, and C. R. Mackay, "Targeting dual-specificity phosphatases: manipulating MAP kinase signalling and immune responses," Nature Reviews Drug Discovery, vol. 6, no. 5, pp. 391-403, 2007.

[31] C. J. Caunt, C. A. Rivers, B. L. Conway-Campbell, M. R. Norman, and C. A. McArdle, "Epidermal growth factor receptor and protein kinase $\mathrm{C}$ signaling to ERK2: spatiotemporal regulation of ERK2 by dual specificity phosphatases," The Journal of Biological Chemistry, vol. 283, no. 10, pp. 6241-6252, 2008.

[32] A. L. Silvers, M. A. Bachelor, and G. T. Bowden, “The role of JNK and p38 MAPK activities in UVA-induced signaling pathways leading to AP-1 activation and c-Fos expression," Neoplasia, vol. 5, no. 4, pp. 319-329, 2003.

[33] K. Shuai and B. Liu, "Regulation of gene-activation pathways by pias proteins in the immune system," Nature Reviews Immunology, vol. 5, no. 8, pp. 593-605, 2005.

[34] K. A. Wilkinson and J. M. Henley, "Mechanisms, regulation and consequences of protein SUMOylation," Biochemical Journal, vol. 428, no. 2, pp. 133-145, 2010.

[35] D. Lim, K. M. Jocelyn, G. W. Yip, and B. H. Bay, "Silencing the Metallothionein-2A gene inhibits cell cycle progression from G1- to S-phase involving ATM and cdc25A signaling in breast cancer cells," Cancer Letters, vol. 276, no. 1, pp. 109-117, 2009.

[36] P. Liu, L. R. Barkley, T. Day et al., "The Chk1-mediated S-phase checkpoint targets initiation factor Cdc45 via a Cdc25A/Cdk2independent mechanism," The Journal of Biological Chemistry, vol. 281, no. 41, pp. 30631-30644, 2006.

[37] A. J. Moss, S. Sharma, and N. P. J. Brindle, "Rational design and protein engineering of growth factors for regenerative medicine 
and tissue engineering," Biochemical Society Transactions, vol. 37, no. 4, pp. 717-721, 2009.

[38] K. Labib, S. E. Kearsey, and J. F. X. Diffley, "MCM2-7 proteins are essential components of prereplicative complexes that accumulate cooperatively in the nucleus during G1-phase and are required to establish, but not maintain, the S-phase checkpoint," Molecular Biology of the Cell, vol. 12, no. 11, pp. 3658-3667, 2001.

[39] T. S. Takahashi, D. B. Wigley, and J. C. Walter, "Pumps, paradoxes and ploughshares: mechanism of the MCM2-7 DNA helicase," Trends in Biochemical Sciences, vol. 30, no. 8, pp. 437444, 2005.

[40] Y. J. Lee and C. Lee, "Stress-activated protein kinases are involved in porcine reproductive and respiratory syndrome virus infection and modulate virus-induced cytokine production," Virology, vol. 427, no. 2, pp. 80-89, 2012.

[41] K. Bhardwaj, P. Liu, J. L. Leibowitz, and C. C. Kao, “The coronavirus endoribonuclease nsp15 interacts with retinoblastoma tumor suppressor protein," Journal of Virology, vol. 86, no. 8, pp. 4294-4304, 2012.

[42] T. D. Friedrich, E. Bedner, Z. Darzynkiewicz, and J. M. Lehman, "Distinct patterns of MCM protein binding in nuclei of $S$ phase and rereplicating SV40-infected monkey kidney cells," Cytometry A, vol. 68, no. 1, pp. 10-18, 2005.

[43] K. Nash, W. Chen, and N. Muzyczka, "Complete in vitro reconstitution of adeno-associated virus DNA replication requires the minichromosome maintenance complex proteins," Journal of Virology, vol. 82, no. 3, pp. 1458-1464, 2008.

[44] W. Stedman, Z. Deng, F. Lu, and P. M. Lieberman, "ORC, MCM, and histone hyperacetylation at the Kaposi's sarcoma-associated herpesvirus latent replication origin," Journal of Virology, vol. 78, no. 22, pp. 12566-12575, 2004.

[45] A. Kawaguchi and K. Nagata, "De novo replication of the influenza virus RNA genome is regulated by DNA replicative helicase, MCM," EMBO Journal, vol. 26, no. 21, pp. 4566-4575, 2007.

[46] D. Yoo, S. K. Wootton, G. Li, C. Song, and R. R. Rowland, "Colocalization and interaction of the porcine arterivirus nucleocapsid protein with the small nucleolar RNA-associated protein fibrillarin," Journal of Virology, vol. 77, no. 22, pp. 1217312183, 2003.

[47] C. Song, R. Lu, D. Bienzle, H. C. Liu, and D. Yoo, "Interaction of the porcine reproductive and respiratory syndrome virus nucleocapsid protein with the inhibitor of MyoD family-a domain-containing protein," Biological Chemistry, vol. 390, no. 3, pp. 215-223, 2009.

[48] T. M. Young, Q. Wang, T. Peery, and M. B. Mathews, "The human I-mfa domain-containing protein, HIC, interacts with cyclin T1 and modulates P-TEFb-dependent transcription," Molecular and Cellular Biology, vol. 23, no. 18, pp. 6373-6384, 2003.

[49] Y. Sun, N. Chen, and D. Yoo, "Inhibition of type I IFN by nsp11 of PRRSV," in Proceedings of the 30th Annual Meeting, American Society of Virology, Twin City, Minn, USA, July 2011. 

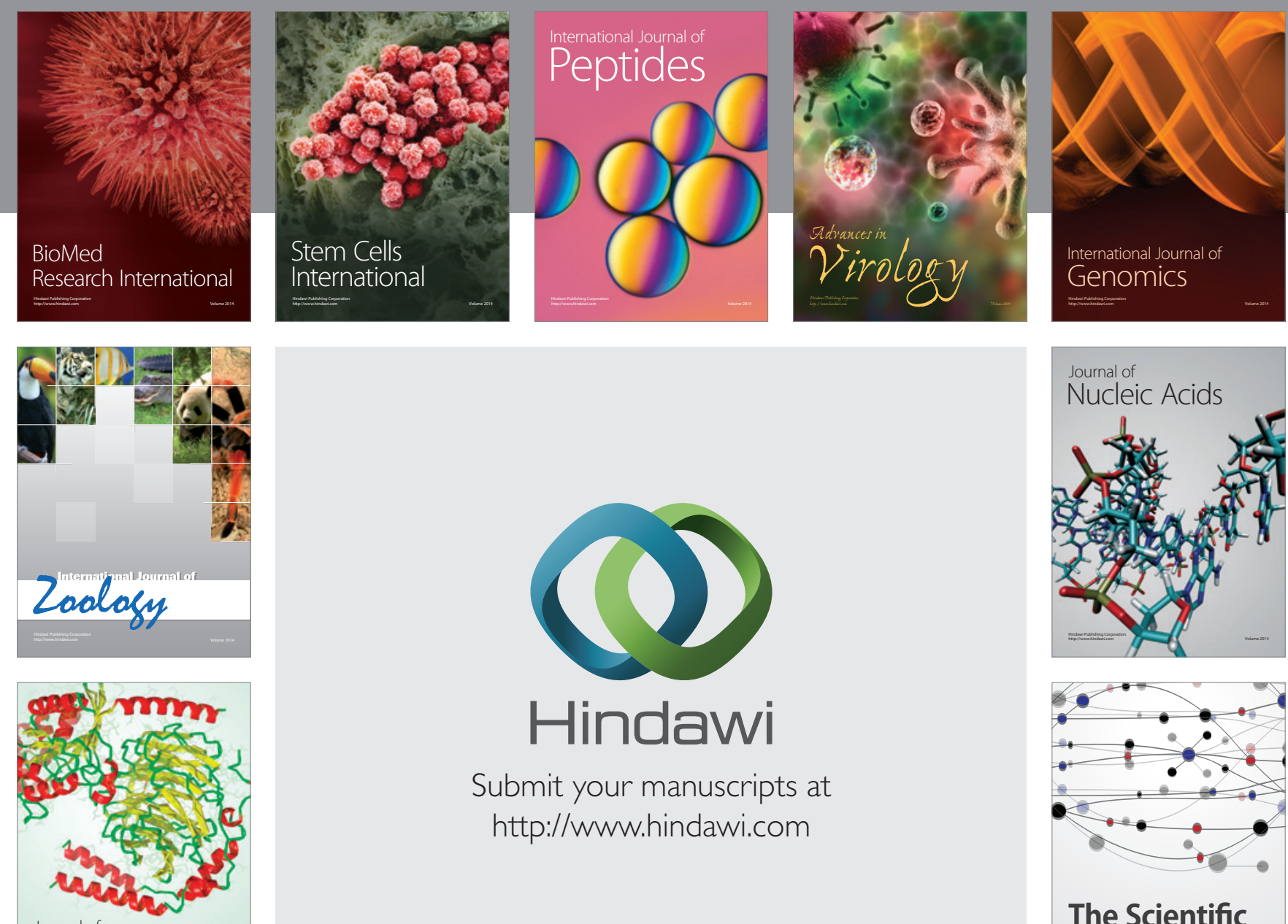

Submit your manuscripts at

http://www.hindawi.com

Journal of
Signal Transduction
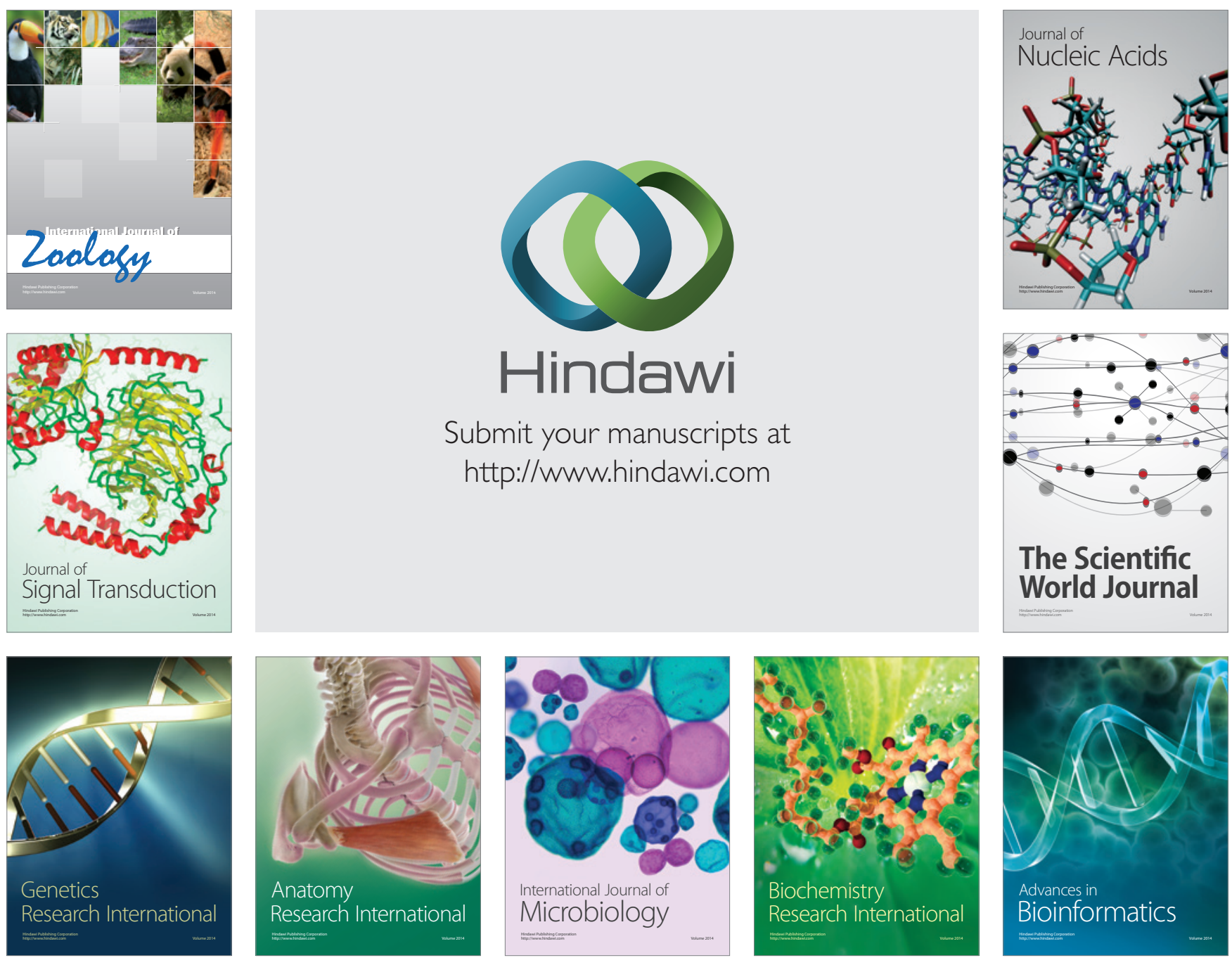

The Scientific World Journal
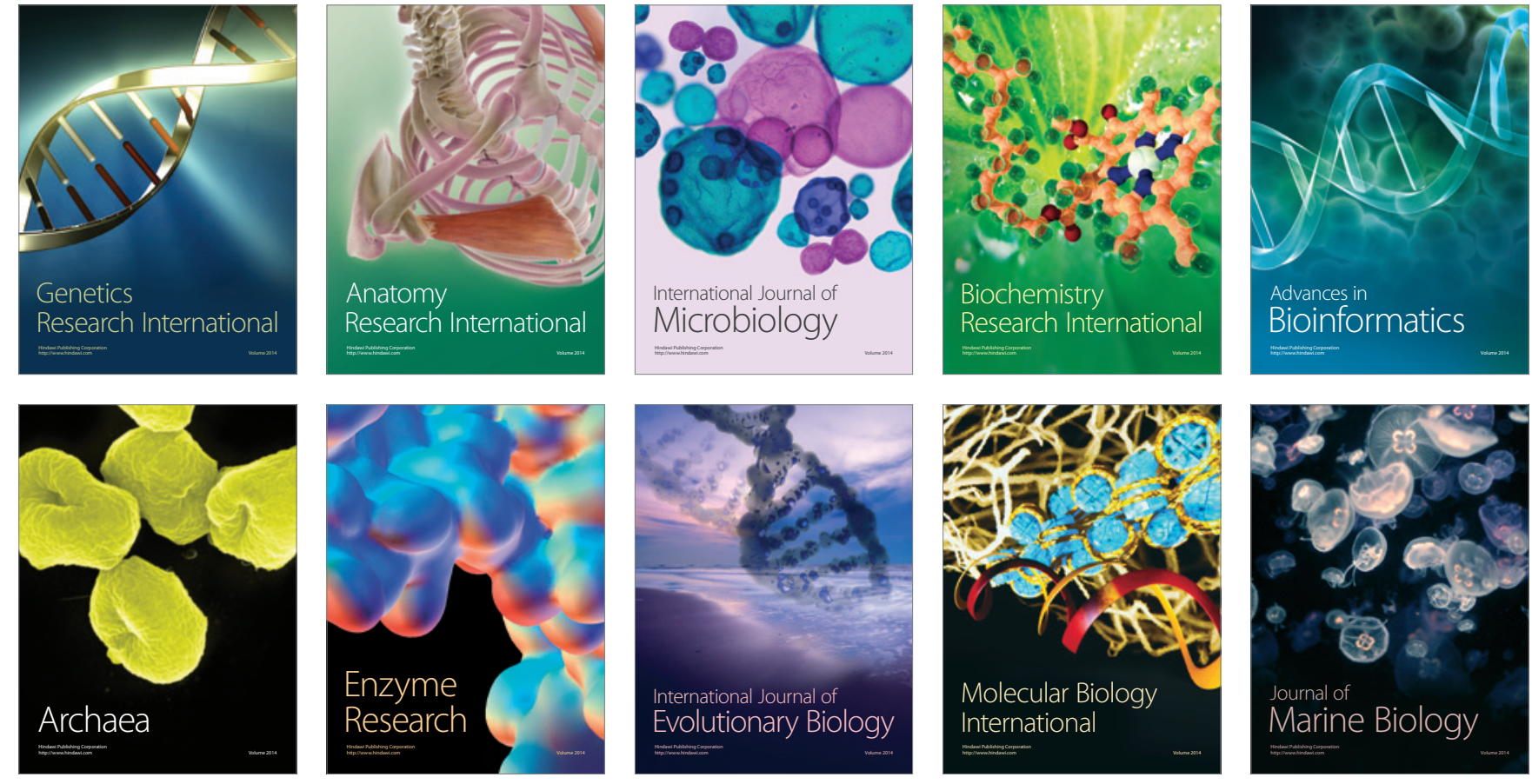